\title{
Head and Neck Paragangliomas: a Narrative Review
}

\author{
Alex Alcaide-Aldeanot and Diego Duminy-Luppi†* \\ University of Barcelonat, School of Medicine, 08036 Barcelona, Spain \\ *Corresponding author: Diego Duminy-Luppi, University of Barcelona, School of Medicine, 08036 Barcelona, Spain
}

\section{Abstract}

Head and neck neoplasms arising in the paraganglion tissue, comprising carotid body, vagal and temporal bone paragangliomas, account for a small part of extraadrenal paragangliomas. They represent, however, a challenging diagnosis that is often made quite late, appearing in some of the most complex anatomical areas with regards to surgery. Morbidity is also high, with often permanent cranial nerves damage or audio-vestibular injury, both by the tumours themselves or as a consequence of late surgery. Therefore, it is important for physicians to be informed as much as possible on this subject. Throughout a vast and thorough assessment of the state-of-the-art advances, as well as some previously published remarkable takes on the matter, this narrative review aims to cover what is needed to know about the epidemiology, pathophysiology, clinical manifestations, diagnosis and treatment of this otorhinolaryngological condition.

Keywords: Head and neck paraganglioma; Paraganglioma; Carotid body tumour; Vagal paraganglioma; Temporal bone paraganglioma; Jugulotympanic paraganglioma; Tympanomastoid paraganglioma; Otorhinolaryngology; Head and neck surgery; Narrative review

\section{Introduction}

Paragangliomas are traditionally poorly defined in literature, as the definition varies depending on the sources. Some more specific designations have recently been revised, such as non-chromaffin (parasympathetic) and metameric (sympathetic), and the term chemodectoma is no longer used [1]. The 2017 WHO classification of tumours of the endocrine organs defines 'extra-adrenal paraganglioma' as both functional (catecholamine secreting) and nonfunctional, sympathetic or parasympathetic-derived neoplasms arising in extra-adrenal paraganglion tissue. Tumours with the same characteristics originated inside the adrenal glands would be referred to as pheochromocytomas [2], although in clinical practice the term 'paraganglioma' generally refers to head and neck tumours with these characteristics [3].

In this review, we will focus on the epidemiology, pathophysiology and clinical manifestations, as well as the diagnosis and treatment of three specific and most frequent types of head and neck paragangliomas (HN-PGLs), consisting of carotid body paragangliomas (CBPs), vagal paragangliomas (VPs) and temporal bone paraganglioma (TBPs), which includes both tympanomastoid (TMPs) and tympanojugular paragangliomas (TJPs). All of them are parasympathetic-derived paragangliomas, with CBP arising from the carotid body at the carotid bifurcation, VP arising mainly (but not only) from the nodose ganglion or inferior ganglion of the vagus nerve. TBPs arise from Jacobson's nerve (i.e. the tympanic branch of CN IX), Arnold's nerve (the auricular branch of $\mathrm{CN} X$ ) and intravagal paraganglia inferior to foramen jugulare [4]. The apparition near the jugular bulb describes TJPs whereas the apparition in the tympanic or mastoid canaliculi describe TMPs [5]. They are indolent slow-growing tumours, mostly non-secreting, in a complex anatomical area [6].

The description of temporal bone paragangliomas has been highly inconsistent, coming from the lack of consensus terminology. The distinction between tympanomastoid and tympanojugular paraganglioma is often unavailable, mentioning 'jugulotympanic paraganglioma' as a sole entity, leaving unclear to the reader if the first is simply dismissed or included in the latter. Others have adopted the terminology 'middle ear paraganglioma', without specifying up to which extent nearby paragangliomas outside of the middle ear are considered. It is however consistent that glomus tympanicum and glomus jugulare are now both 
included and referred to as jugulotympanic paraganglioma. We will therefore mention as temporal bone paraganglioma all tympanomastoid paragangliomas, tympanojugular or jugulotympanic paragangliomas, temporal paragangliomas and jugular foramen paragangliomas, specifying the subtype only when the information refers to that specific subtype exclusively. Finally, 'Head and neck' is commonly defined as the anatomical area delimitated inferiorly by the clavicle and superiorly by the cranial vertex, and so does this review [7].

\section{Methods}

Resource publications for this narrative review were identified and selected through searches of PubMed and MEDLINE, using 'cervical paraganglioma', 'paraganglioma', 'head and neck paraganglioma', 'vagal paraganglioma', 'carotid body paraganglioma', 'carotid body tumor', 'glomus jugulare', 'temporal bone paraganglioma', 'jugular foramen paraganglioma', 'middle ear paraganglioma', 'glomus tympanicum' and 'jugulotympanic paraganglioma' as search terms. Studies selected for this review include the most recent advances in research until November 2019, they were published in high-impact, peer-reviewed journals, and showed results based on satisfactory numbers of study participants, covering a relevant population.

\section{Epidemiology}

The incidence of head and neck paragangliomas in the general population ranges from $1 / 30.000$ to $1 / 100.000$ per year. CBPs account for approximately $60 \%$ and TBPs account for $30 \%$ of them, leaving approximately $10 \%$ to VPs. Laryngeal paragangliomas are extremely rare, with less than 100 cases reported in literature. The remaining ones (nonhead and neck) are mostly found in the abdomen region [8-11]. Only $10 \%$ of paragangliomas do not occur in the adrenal paraganglia and are thus not pheochromocytomas. Of these, $97 \%$ arise in non-head and neck locations [12].

$60 \%$ of HN-PGLs are sporadic, although the remaining $40 \%$ are familial inherited cases associated with succinate dehydrogenase subunits mutations [10]. These familial cases are more likely to be bilateral and multiple (10-25\% for CBPs and $20-40 \%$ for VPs, $30 \%$ for TBPs). Only $5 \%$ of cervical paragangliomas are catecholamines producers. Malignant behaviour isn't predictable by clinical manifestations nor histology, although familial cases are associated with higher rates of malignancy than sporadic ones [8-10]. The pathologies most associated with paragangliomas are type 2B Multiple Endocrine Neoplasia (MEN), type 1 neurofibromatosis and Von Hippel-Lindau syndrome [8,9].

CBPs appear between the 5th and 6th decade of life, show approximately 2:1 (female:male) gender predilection and are rarely bilateral if sporadic (5\%) [10]. VPs usually appear during the 5th decade of life, also show 2:1 (female:male) gender predilection and have higher chances of being bilateral/multifocal or metastatic than CBPs [10].

TBPs also usually appear between the 5th and 6th decades of life and exhibit female gender predilection with a female:male ratio of 3:1 [10,12]. Jugular paragangliomas have their peak incidence in the 6th decade, and some authors point at a higher female to male ratio, as high as 4:1 or $6: 1[10,13,14]$. Bimodal distribution of cases in tympanic paraganglioma has been mentioned, with a first smaller peak around the 4th decade [15]. Malignant TBP cases are lower than in other HN-PGLs, and often associated to SDHB mutations. These range from $2-5 \%$ and come from the presence of metastases, as proliferative index Ki67 is almost always very low, around $1-2 \%[5,13,16]$. Interestingly, the incidence of cervical paragangliomas is higher in people living above $1.000 \mathrm{~m}$ over the sea level, as encountered in a single cohort study, postulating a potential role of chronic hypoxia as a risk factor for CP [17].

\section{Pathophysiology}

Cervical paragangliomas are a rare group of tumours, originated from the chromaffin cells of the extra-adrenal paraganglionic system (derived originally from the crista neuralis), following the autonomous system chain over the head and neck. They are slowly growing and invasive to nearby structures, and consist of highly vascularized structures, getting its blood supply mainly from external carotid artery branches [18].

To elucidate the aetiology, it's mandatory to separate between the familial and the sporadic cases. As mentioned before, the familial cases are related to succinate dehydrogenase (SDH) mutations in 4 locus: 11q23 (SDHD gene causing PGL1), 11q13 (PGL2), 1q21 (SDHC gene causing PGL3) and 1p36.1p35 (SDHB gene causing PGL4 [19]. The inheritance pattern is autosomal dominant, with incomplete penetrance [20].SDH plays a role in the tricarboxylic acid cycle and oxidative phosphorylation located in the mitochondrial complex II. The mutation in SDH produces similar effects as chronic hypoxia in paraganglionic cells [21]. Mutations in SDHD and SDHB increase intracellular concentrations of hypoxia molecular mediators (HIF) and stimulate angiogenic genes (VEGF) that translate into an increased hyperplasic proliferation, causing the neoplasia [19]. SDHD mutations are more common in multifocal paragangliomas, including non-functional ones, whereas SDHB mutations are more associated with malignant behaviours [22]. Finally, the SDHA subunit mutation hasn't been related with paragangliomas

Citation: Alex Alcaide-Aldeano, Diego Duminy-Luppi` . Head and Neck Paragangliomas: a Narrative Review. Op Acc J Bio Sci \& Res 7(1)-2021. 
nor other tumours, but with the autosomal recessive young encephalopathy [23].

Macroscopic pathology of paragangliomas appears as well-circumscribed reddish-brown masses usually ranging from 2 to 6 centimetres at resection [6]. Rarely, the tumour can be pigmented [14]. Jugular paragangliomas had an average size of 3.5 centimetres in a large retrospective study, whereas tympanic paragangliomas had considerably a smaller size with a mean of 0.7 centimetres [11].

Microscopic pathology shows a characteristic 'Zellballen' pattern composed by nests of neuroendocrine chief cells and peripheral glial-like sustentacular cells, surrounded by delicate vascular septae. Both types of cells are positive to immunochemistry staining with chromogranin, synaptophysin, neuron-specific enolase, CD56 and CD57 (chief cells) and S-100 (sustentacular cells). Antibodies against proteins encoded by recognised susceptibility genes (as previously mentioned) may also be used to establish an increased risk of germline mutations of these genes [24].

\section{Clinical Manifestations}

Clinical manifestations of head and neck paragangliomas are not so obvious, and whereas functional tumours are often suspected with the presentation of otherwise unexplained fluctuating or persistent specific symptoms such as headache, profuse sweating, palpitations, tachycardia, hypertension or anxiety, these only represent $1 \%$ of HN-PGLs, as even catecholamine secreting tumours often don't reach high enough levels to produce symptoms $[25,26]$. Most CBPs and VPs are thus non secreting at a clinically-significant level and grow on average at a rate of $0.83 \mathrm{~mm} /$ year. Clinical manifestations mostly come from the compression or invasion of nearby structures, depending on the direction of the growth [6]. TBPs also exhibit a similar slow growth, but often present in a symptomatic fashion. However, diagnosis is usually made after a considerable time, with patients waiting on average around 30 months before consultation $[12,27]$.

The most common presentation of CBPs is that of an asymptomatic, pulsatile cervical mass, with a limited mobility in the cephalocaudal axis and good mobility in the lateral axis (classically referred to as Fontaine's sign). In some cases, headache and syncope have also been reported as main complaints [28]. Early detection through physical examination or self-detection may be challenging especially in obese patients. Bulging of the oropharyngeal wall is present in approximately $10 \%$ of tumours, originating hoarseness, dysphagia or foreign body sensation. Larger CBPs may cause vagal and hypoglossal palsy, and the compression of arteries may result in a noticeable bruit. Differential diagnosis of these masses includes carotid aneurysms and neurilemmomas [14].

VPs also present as painless cervical masses, and occasionally patients will show dysphagia and hoarseness. Oropharynx may be deviated following the occupation of parapharyngeal space. Cranial nerve (CN) dysfunction occurs more frequently than with CBPs, with preoperative weakness of CN X occurring in one third of patients $[14,29]$. In some cases, other CNs may be involved, such as CN IX, and although rare, the involvement of the sympathetic chain can cause Horner's Syndrome. Also rare but of major importance, VPs may reach the skull base and extend intracranially (dumbbell-shaped tumour), or involve the jugular foramen and the atlas [6]. Polymyalgia rheumatica is a described paraneoplastic syndrome associated with benign VP [30].

TBPs usually present as symptomatic tumours. Depending on their location and extension, symptoms may vary, as these appear based on the structure they alter by compression or erosion. Jugular paragangliomas will have higher rate of $\mathrm{CN}$ dysfunction, whereas tympanic paragangliomas will have significantly higher hearing symptoms. Both can however extend into the other's anatomical area, ultimately behaving in a similar manner [11]. Most commonly reported symptoms are pulsatile tinnitus ranging from 60 to $80 \%$ of patients, and hearing loss, in 55 to $80 \%$ of patients $[5,13-15,27]$. Conductive hearing loss is predominant, whereas neurosensorial hearing loss is less frequent and shows itself in extended tumours with vestibular involvement $[13,27]$. Aural fulness is also frequently reported, in up to $70 \%$ of patients $[10,15]$. $\mathrm{CN}$ abnormalities are often present, in up to $40 \%$ of patients $[5,16]$. These will show up in a clinical examination, or through a wide variety of symptoms such as dysphonia, dysphagia, dysarthria, tongue weakness, hoarseness and shoulder pain or weakness [12-15,31]. Specifically, CN VII is affected in up to $39 \%$ of patients, CN IX and X in up to $40 \%$ of patients, and $\mathrm{CN} \mathrm{XI}$ and XII in up to $30 \%$ of patients [5] Both Vernet syndrome (CN IX, X, XI abnormality) as well as Collet-Sicard syndrome (CN IX, X, XI, XII abnormality) have been described associated to TBPs, with the latter in up to $10 \%$ of jugular paragangliomas [13].

Some authors have considered the presence of a red, vascular middle-ear mass as pathognomonic of TBP, whereas others simply describe it as very common finding $[5,14]$. This mass can also be pulsatile $[5,14,15]$. Other characteristic sings are Brown's sign, described as a blanching of the lesion 
when pneumatic pressure is applied, revealing the vascular nature of the tumour, and the rising sun sign, presenting as an inferior semi-circular red-blue lesion behind the tympanic membrane $[5,15]$. Rarer presentations may be vertigo (in up to $20 \%$ ), otalgia (3\%), otorrhagia (1.5-9.6\%) and epistaxis (uncommon) $[15,27]$. Horner's syndrome can also be seen [16].

CBPs' malignancy rate is estimated between 5-10\%. Pain, young age and rapid enlargement are the most predictive features. Although a retrospective cohort study reported a CBP with aggressive soft tissue invasion which affected the brachial plexus and cervical nerve roots, this is generally not accepted as a malignant CBP; malignancy requires the presence of regional or distant metastasis $[11,29]$.

Metastatic CBP and VPs are rare but represent a challenging medical management. VPs are more like to become malignant and metastasize than CBPs [32]. Described locations of metastatic CBP include peripheral lymph nodes or distant organs such as liver, bone, kidney, lungs, breast, pancreas, brain and thyroid gland [28,33]. Wang et al. mentioned what they believe to be the first case of CBP brain metastasis, with the particularity of having an endocrine activity [33]. The symptoms described were right limb weakness, dizziness, vomiting, hypertension and hyperglycaemia, resolving after the tumour extirpation. Needless to say, these are not the common rule. TBPs have even lower metastatic rates than CBPs, although some cases have been reported, especially in bone, lungs, lymph nodes and liver [5].

Differential diagnosis of CBPs include lymph nodes, which may or may not contain metastatic disease, mainly from other neuroendocrine tumours such as neuroendocrine carcinomas, Merkel cell carcinoma and medullary thyroid carcinoma. For VPs, differential diagnosis can be established with schwannomas, vascular tumours and parotid gland salivary tumours. When investigating a possible TBP, clinicians should keep in mind that meningioma, middle ear adenoma and haemangioma can present in a similar manner and share part of neuroendocrine markers [10]. Also, an inflammatory polyp, an aberrant internal carotid artery, an anatomic variation of the jugular bulb, a CN VII neuroma, an osteoma, a cholesteatoma or a cholesterol granuloma can be misdiagnosed as a TBP [27].

HN-PGLs may be hard to distinguish from atypical carcinoids, although some characteristics may help differentiate both: atypical carcinoids usually appear during the 6th-7th decade, metastasize frequently and primarily affect male patients ( $3: 1 \mathrm{M}: \mathrm{F})$, although they have the same clinical manifestations and ultimately require histologic analysis [10].

\section{Diagnosis}

As mentioned before, although clinically non-secreting, HN-PGLs may secrete catecholamines, which justifies why biochemical tests such as plasma free metanephrines or urinary fractionated metanephrines are recommended as initial investigation for paragangliomas [34]. Imaging studies should be performed once a positive biochemical test occurs, and include both contrast enhanced CT or Magnetic Resonance Imaging [34]. MRI is preferred in $\mathrm{HN}$ PGLs, with a sensitivity of $90-95 \%$ (higher than CT), and it helps differentiate HN-PGLs from other tumours (such as Schwannoma, neurofibroma, carotid artery aneurism), and provides excellent details on extension and vascularization $[4,34,35]$. CBPs and TBPs show a characteristic salt-andpepper image in contrast in T1 MRI, distinguishing areas with subacute haemorrhage and slow blood flow ('salt') from serpent-shaped flow voids ('pepper'). Gadolinium intensively enhances these lesions, and T2 shows mildly and heterogeneously hyperintense, well defined mass [4$6,15,35]$.

If the invasion of the skull base is suspected, contrast enhanced CT provides excellent spatial resolution. MRI can be, and usually is, complementary to CT [6]. CBPs appear as a hypervascular mass that spreads between the internal and the external carotid arteries. However, it is usually located at the same level or below the carotid bifurcation, not above. Digital subtraction angiography may be performed to evaluate internal carotid infiltration or preoperatively if embolization is considered. The image is classically described as a 'lyre sign', and CBPs show a slow and prolonged blush. VPs can also appear as CBPs but they usually present behind the internal carotid artery and push the vessels in an anteromedial direction $[4,6,29,35]$. Another characteristic is that they may separate the jugular vein from the carotid sheath [29].

In TBPs, radiologic studies are also paramount in order to further classify the tumour and determine the most appropriate approach to treatment. High-resolution CT scan with contrast is both sensitive and specific, usually showing localized irregular bone destruction at the jugular foramen, with sometimes enlargement of the latter. This pattern is traditionally described as 'moth-eaten' $[4,5]$. TBPs are a soft tissue mass, enhanced by contrast [35]. The erosion of the jugular plate suggests that the tumour is a jugular paraganglioma [36]. MRI is preferred and complementary to CT in order to precisely determine intracranial 
involvement, especially in those tumours reaching outside of the middle-ear [5,15,35]. Furthermore, MRI differentiates more accurately tympanic paragangliomas from jugular paragangliomas [5,12]. Angiography is not always performed, but can be considered in case of suspected invasion of the internal carotid artery, or the anterior vertebral artery [5]. Tympanic paragangliomas may grow inside the tympanic cavity without destroying the ossicles, but being attached to them $[4,15]$.

Ultrasound, if performed, shows solid hypoechoic lesions [35]. Biopsy of suspected PGLs is contraindicated because of the high risk of bleeding [37]. For metastatic cases, 18FDG PET-CT is preferred because of its higher sensitivity when compared to other techniques, especially in SDHB-related PPGLs [34].

\section{Treatment}

There is widespread consensus in the literature with regards to surgery as the only available option for treatment. There is no effective medical therapy.

Shamblin et al [38]. suggested a classification in 1971 based on CBP tumour size and carotid artery invasion to assess resection possibilities:

1. Shamblin 1: Less frequent group, containing small size $(<4 \mathrm{~cm})$ and well localized tumours, without invasion of major vessels and easily resectable.

2. Shamblin 2: Nearly $50 \%$ of the cases, containing of mid-size $(>4 \mathrm{~cm})$ tumours, adhered to or partially surrounding major vessels. They compress the internal and external carotid artery but can be removed through a cautious subadventitial dissection.

3. Shamblin 3: More than $25 \%$ of the cases, containing big size tumours, invading carotids and nearby structures. In order to be completely removed, partial or total resection of these structures is needed.

The reasons to resect a cervical paraganglioma include the following: [39]

1. Some HN-PGLs could eventually become malignant, although it's not possible to know before or after the surgery.

2. There is no true consensus on an optimal follow-up strategy.

3. No cases of spontaneous regression, even correcting hypoxemia, have been published.

4. The risk of vascular injury in experienced surgical teams intervening a Shamblin 1 tumour is minimal.

\section{All tumours can become symptomatic.}

The basic surgical technique consists of an incision over the anterior edge of sternocleidomastoid muscle. The deep anterior fascia is dissected in order to expose the common carotid artery, which is important for an early vascular control. The dissection plane then extends anteriorly until the carotid bifurcation. This way the subadventitial plane or 'white line' as described by Gordon-Taylor can be identified, which allows a fine separation of the tumour and the artery due to a relatively avascular plane $[39,40]$.

The risk of an arterial injury during the resection increases with tumour size, but without a significative increase of brain ischaemic events. Adjacent $\mathrm{CN}$ lesions are one of the major risks during surgery, mainly accessory spinal nerve $(\mathrm{XI})$, vagus nerve $(\mathrm{X})$ and hypoglossal nerve (XII). Again, the risk increases with tumour size, but locating, isolating and carefully dissecting these structures prior to tumour resection decreases the risk. In vast tumours, where surgical resection could entail bigger morbidity, or in suboptimal basal patients, either because of age or because of concomitant pathologies, radiotherapy is indicated, with $45 \mathrm{~Gy}$ in 25 fractions showing good results in/at stopping tumour progression at 5 and 10 years of follow-up (only 4 to $6 \%$ recurrence at 5 and 10 years respectively), but sometimes leaving an asymptomatic residual mass [39,41,42]. Regarding potential complications of radiotherapy, histologic examination has shown that chief cells are minimally affected by irradiation, although the distinctive vascular structure of the tumour is replaced by fibrous connective tissue, raising awareness over the appearance of malignant tumours such as fibrosarcoma [4345]. $15 \%$ of patients who underwent radiotherapy suffered at least one complication, which include inflammation of the external auditory canal and middle ear, skin loss with bone exposure, osteoradionecrosis, cranial nerve neuropathies (specially hearing and taste loss, in $<3 \%$ ) and direct injury to brain tissue, among others. Additionally, it is worth mentioning that if radiotherapy fails, surgery will be more difficult $[40,42,45-47]$. For CBPs, $14 \%$ of $<5 \mathrm{~cm}$ tumours extirpation entail $\mathrm{CN}$ disfunction as compared to $67 \%$ of $>5 \mathrm{~cm}$ tumours [12].

Another alternative worth mentioning is embolization, a technique consisting in introducing a catheter (generally through a percutaneous approach to the femoral vessels with Seldinger technique) to deploy coils in tumour's vascularisation that will form a clot and interrupt blood flow, reducing blood loss and facilitating tumour resection.

Citation: Alex Alcaide-Aldeano, Diego Duminy-Luppi* . Head and Neck Paragangliomas: a Narrative Review. Op Acc J Bio Sci \& Res 7(1)-2021. 
The procedure is usually undergone $48 \mathrm{~h}$ before surgery to avoid intraoperatory inflammatory phenomena. There have been some controversial discussions regarding its efficacy, since it also entails some risks (distal embolization, necrosis, cerebral or ocular infarcts, etc.), so there is no real general consensus over the existing evidence [48].

For VPs, the same management options are generally considered. However, surgery isn't supported by high levels of evidence, especially when compared to small CBPs, because an intervention almost always (93\%) implies complete resection of the vague nerve which causes serious side effects such as unilateral vocal fold paralysis, pharyngeal plexus deficit, pharynx numbness and soft palate dysfunction, resulting in dysphagia and dysphonia among others, often worse than the tumour itself would cause. The typical approach is lateral, transcervical and preauricular, sometimes superiorly extended. Damage to other $\mathrm{CNs}$ is also possible, with numbers ranging from $21 \%$ to $39 \%$. When compared to Radiotherapy (RT) and Stereotactic Radiosurgery (SRS), results are similar to surgery but with less damage to $\mathrm{CN}$, postulating the option of an observation $\pm \mathrm{RT} \pm \mathrm{SRS}$ as a reasonable alternative to surgery in selected patients [12]. A recent study has shown that immediate selective laryngeal reinnervation using the phrenic nerve and the ansa cervicalis as donor nerves after VP excision improves both dysphagia and dysphonia. [49] However, further evidence is needed to define management algorithms for VPs.

Regarding TBPs, the modified Fisch and Mattox classification is used to divide them based on their extension, which at the same time determines the optimal surgical approach (presented between brackets). Tympanomastoid paragangliomas, on the one hand, can be classified as class $A$, if they are confined to middle ear, and then further subdivided into $A 1$ if the tumour margins are clearly visible on otoscopic examination (transcanal approach) or into A2 if margins are not visible on otoscopy (retroauricular-transcanal approach, glove finger flap technique). An emerging new technique, consisting of transcanal endoscopic minimally invasive surgery, has demonstrated feasibility and promising results among this class [50-52]. They can also be classified as class B if they are confined to the tympanomastoid cavity without bone destruction in the temporal infralabyrinthine compartment, and then further subdivided into B1 if they extend to the hypotympanum alone (canal wall up mastoidectomy with posterior tympanotomy), into B2 if they extend to the hypotympanum and the mastoid (canal wall up mastoidectomy with posterior tympanotomy and subfacial recess tympanotomy) or into B3 if they erode the carotid canal (subtotal petrosectomy with middle ear obliteration). [27]. Major postoperative complications such as $\mathrm{CN}$ deficits are usually not expected, but minor complications such as postoperative conductive hearing loss may occur [53].

Tympanojugular paragangliomas, on the other hand, can be classified as class $C$ if they extend beyond the tympanomastoid cavity, destroying bone of the infralabyrinthine and apical compartment of the temporal bone and involving the carotid canal, with further subdivisions $\mathrm{C} 1-\mathrm{C} 4$ depending on the degree of invasion (C1, tumours with limited involvement of the vertical portion of the carotid canal; $\mathrm{C} 2$, tumours invading the vertical portion of the carotid canal; $C 3$, tumours with invasion of the horizontal portion of the carotid canal; $\mathrm{C} 4$, tumours reaching the anterior foramen lacerum). They can also be classified as class $D$ if they extend intracranially (De1, tumours up to $2 \mathrm{~cm}$ dural displacement; De2, tumours with more than $2 \mathrm{~cm}$ dural displacement; Di1, tumours up to $2 \mathrm{~cm}$ intradural extension; Di2, tumours with more than $2 \mathrm{~cm}$ intradural extension; Di3, tumours with inoperable intradural extension) or as class $\mathrm{V}$ if they involve the vertebral artery (Ve, tumours involving its extradural portion; Vi, tumours involving its intradural portion) [5]. They are usually resected via an infratemporal approach, but C1, C2, De1, De2, Di1 and Di2 may demand a variant of the juxtacondylar approach [54]. Because these tumours are adherent and occasionally CN IX-XII are involved, higher rates of $\mathrm{CN}$ deficits are anticipated for the postoperative outcome, and thus possibly requiring further surgical procedures attempting to correct them $[55,56]$. Di1 and Di2 tumours should be generally resected in a twostage multidisciplinary procedure involving neurosurgeons, whereas in Di3 tumours palliative radiotherapy is advocated. Although some inconsistencies regarding Fisch classification and follow-up intervals among different studies must be taken into account, long-term success rate following surgical therapy of tympanojugular paragangliomas is 72-95\% [54].

\section{Conclusion}

Paragangliomas are functional or non-functional, sympathetic or parasympathetic-derived neoplasms arising in extra-adrenal paraganglion tissue. Amongst these, HN-PGLs are mainly composed by CBPs, VPs, and TBPs. Some genetic associations have been described. Clinical manifestations are diverse although some signs and symptoms strongly suggest the diagnosis. Biochemical screening is the first complementary step when investigating a possible HN-PGL, followed, if positive, by the best available imaging technique, which usually narrows down the differential diagnosis. Surgical intervention, with or without previous embolization, is the best and only approved therapeutic option for CBPs and TBPs, whereas 
for VPs further evidence is needed to determine whether surgery with reinnervation or a combination of RT and SRS is the best therapeutic management strategy. For some tympanomastoid paragangliomas, endoscopic surgery is emerging with promising results.

\section{References}

1. Lin D, Carty SE, Loeffler JS (2019) Paragangliomas: Epidemiology, clinical presentation. diagnosis, and histology. UpToDate 1: 1-48.

2. Neumann HPH, Young WF, Eng C (2019) Pheochromocytoma and paraganglioma. N Engl J Med 381(6): 552-565.

3. Jameson JL, Fauci AS, Kasper DL, Hauser SL, Longo DL, Jameson JL, et al (2018) Harrison's principles of internal medicine [Internet].

4. Zuluaga A, Ocazionez D, Riascos R, Palacios E, Restrepo CS (2014) Paragangliomas of the Head and Neck: Imaging Assessment. Ear, Nose Throat J 93(8): E22-4.

5. Prasad SC, Paties CT, Schiavi T, Esposito DL, Lotti LV, MarianiCostantini R, et al. (2019) Tympanojugular Paragangliomas: Surgical Management and Clinicopathological Features. In: Paraganglioma: A Multidisciplinary Approach. Codon Publications 99-123.

6. Prasad SC, Paties CT, Pantalone MR, Mariani-Costantini R, Sanna M (2019) Carotid Body and Vagal Paragangliomas: Epidemiology, Genetics, Clinicopathological Features, Imaging, and Surgical Management. In: Publications C, editor. Paraganglioma: A Multidisciplinary Approach. Codon Publications p. 81-98.

7. Standring S, Gray H (2008) Chapter 25: Head and neck: overview and surface anatomy. In: Standring S, Gray H, editors. in Gray's anatomy: the anatomical basis of clinical practice. 40th Editi. Edinburgh: Churchill Livingstone/Elsevier 405.

8. Lack EE, Cubilla AL, Woodruff JM, Farr HW (1977) Paragangliomas of the head and neck region. A clinical study of 69 patients. Cancer 39(2): 397-409.

9. Luna-Ortiz K, Rascon-Ortiz M, Villavicencio-Valencia V, GranadosGarcia M, Herrera-Gomez A (2005) Carotid body tumors: review of a 20-year experience. Oral Oncol 41(1): 56-61.

10. Williams MD (2017) Paragangliomas of the Head and Neck: An Overview from Diagnosis to Genetics. Head Neck Pathol 11(3): 278-87.

11. Smith JD, Harvey RN, Darr OA, Prince ME, Bradford CR, Wolf GT, et al. (2017) Head and neck paragangliomas: A two-decade institutional experience and algorithm for management. Laryngoscope Investig Otolaryngol 2(6): 380-389.

12. Moore MG, Netterville JL, Mendenhall WM, Isaacson B, Nussenbaum B (2016) Head and Neck Paragangliomas: An Update on Evaluation and Management. Otolaryngol Head Neck Surg 154(4): 597-605.

13. Persky M, Tran T (2018) Acquired Vascular Tumors of the Head and Neck. Otolaryngol Clin North Am 51(1): 255-274.

14. Pellitteri $P$ (2004) Paragangliomas of the head and neck. Oral Oncol 40(6): 563-575.

15. Sweeney AD, Carlson ML, Wanna GB, Bennett ML (2015) Glomus tympanicum tumors. 48(2) :293-304.

16. Weber PC, Patel S (2001) Jugulotympanic Paragangliomas. Skull Base Tumor Surg 34(6): 1231-1240.

17. Astrom K, Cohen JE, Willett-Brozick JE, Aston CE, Baysal
BE (2003) Altitude is a phenotypic modifier in hereditary paraganglioma type 1: evidence for an oxygen-sensing defect. Hum Genet 113(3): 228-37.

18. Gil-Carcedo E, Gil-Carcedo LM, Vallejo LA, Herrero D, Ortega C (2006) Diagnóstico y tratamiento de los paragangliomas carotídeos. Presentación de nueve casos y revisión de la literatura. Acta Otorrinolaringol Esp 57(9): 412-418.

19. Sevilla García MA, Pendás JLL, Tapia JPR, García-Rostán G, Fente VS, Pelaz AC, et al. (2007) Paragangliomas de cabeza y cuello: Revisión de 89 casos en 73 pacientes. Acta Otorrinolaringol Esp 58(3): 94-100.

20. Lack EE (1997) Armed Forces Institute of Pathology (U.S.), Universities Associated for Research and Education in Pathology. Tumors of the adrenal gland and extra-adrenal paraganglia. Armed Forces Institute of Pathology $468 \mathrm{p}$.

21. Wieneke JA, Smith A (2009) Paraganglioma: Carotid Body Tumor. Head Neck Pathol 3(4): 303-306.

22. Kollert M, Minovi AA, Draf W, Bockmühl U (2006) Cervical paragangliomas-tumor control and long-term functional results after surgery. Skull Base 16(4): 185-91.

23. Bourgeron T, Rustin P, Chretien D, Birch-Machin M, Bourgeois M, Viegas-Péquignot E, et al. (1995) Mutation of a nuclear succinate dehydrogenase gene results in mitochondrial respiratory chain deficiency. Nat Genet 11(2): 144-149.

24. Kumar V, Abbas AK, Aster JC, Perkins JA. Robbins and Cotran pathologic basis of disease. $1391 \mathrm{p}$.

25. McNicol AM (2011) Update on tumours of the adrenal cortex, phaeochromocytoma and extra-adrenal paraganglioma. Histopathology 58(2): 155-68.

26. Asa S, Ezzat S, Mete O (2018) The Diagnosis and Clinical Significance of Paragangliomas in Unusual Locations. J Clin Med 7(9): 280.

27. Sanna M, Fois P, Pasanisi E, Russo A, Bacciu A (2010) Middle ear and mastoid glomus tumors (glomus tympanicum): An algorithm for the surgical management. Auris Nasus Larynx. 37(6): 661-8.

28. Kaygusuz I, Karlidag T, Keles E, Yalcin S, Yuksel K (2015) Carotid body tumor: Clinical features. J Craniofac Surg 26(7):e586-e588.

29. Chan Y, Goddard JC (John C. K.J) (2012) Lee's Essential otolaryngology: head \& neck surgery 1211 p.

30. L'Huillier V, Mauvais O, Valmary-Degano S, Tavernier L (2017) Polymyalgia rheumatica and vagal paraganglioma. Eur Ann Otorhinolaryngol Head Neck Dis 134(6): 427-30.

31. Suárez C, Sevilla MA, LlorenteJL(2007) Temporal paragangliomas. Eur Arch Oto-Rhino-Laryngology 264(7): 719-31.

32. Heyes R, Taki N, O'Leary MA (2017) Vagal Paraganglioma Presenting as a Neck Mass Associated with Cough on Palpation. Case Rep Otolaryngol 2017: 1-4.

33. Wang X, Zhu X, Chen J, Liu Y, Mao Q (2019) Metastatic brain carotid body paraganglioma with endocrine activity: a case report and literature review. Br J Neurosurg 33(3): 269-71.

34. Lenders JWM, Duh QY, Eisenhofer G, Gimenez-Roqueplo AP, Grebe SKG, Murad MH, et al. (2014) Pheochromocytoma and paraganglioma: An endocrine society clinical practice guideline. J Clin Endocrinol Metab 99(6): 1915-42.

35. Griauzde J, Srinivasan A (2015) Imaging of Vascular Lesions of the Head and Neck. Vol. 53, Radiologic Clinics of North America. W.B. Saunders 197-213.

36. Woolen S, Gemmete JJ (2016) Paragangliomas of the Head and 
Neck. Neuroimaging Clin NA 26: 259-278.

37. Darouassi Y, Alaoui M, Mliha Touati M, AL Maghraoui O, En-nouali A, Bouaity B, et al. (2017) Carotid Body Tumors: A Case Series and Review of the Literature. Ann Vasc Surg 43(May): 265-71.

38. Shamblin WR, ReMine WH, Sheps SG, Harrison EG (1971) Carotid body tumor (chemodectoma). Clinicopathologic analysis of ninety cases. Am J Surg 122(6): 732-739.

39. Knight TT, Gonzalez JA, Rary JM, Rush DS (2006) Current concepts for the surgical management of carotid body tumor. Am J Surg 191(1): 104-10.

40. Köhler HF, Carvalho AL, Mattos Granja N V, Nishinari K, Kowalski LP (2004) Surgical treatment of paragangliomas of the carotid bifurcation: results of 36 patients. Head Neck 26(12): 10581063.

41. Netterville JL, Reilly KM, Robertson D, Reiber ME, Armstrong WB, Childs P (1995) Carotid body tumors: a review of 30 patients with 46 tumors. Laryngoscope 105(2): 115-26.

42. Hinerman RW, Amdur RJ, Morris CG, Kirwan J, Mendenhall WM (2008) Definitive radiotherapy in the management of paragangliomas arising in the head and neck: A 35-year experience. Head Neck 30(11): 1431-1438.

43. Lalwani AK, Jackler RK, Gutin PH (1993) Lethal Fibrosarcoma Complicating Radiation Therapy for Benign Glomus Jugulare Tumor. Am J Otol 14(4): 398-402.

44. Patetsios P, Gable DR, Garrett W V., Lamont JP, Kuhn JA, Shutze WP, et al. (2002) Management of carotid body paragangliomas and review of a 30-year experience. Ann Vasc Surg 16(3): 331338.

45. Destito D, Bucolo S, Florio A, Quattrocchi C (2012) Management of head and neck paragangliomas: A series of 9 cases and review of the literature. Ear, Nose Throat J 91(8): 366-375.

46. Noujaim SE, Pattekar MA, Cacciarelli A, Sanders WP, Wang AM (2000) Paraganglioma of the temporal bone: Role of magnetic resonance imaging versus computed tomography. Top Magn Reson Imaging 11(2): 108-122.
47. Thabet MH, Kotob H (2001) Cervical paragangliomas: Diagnosis, management and complications. J Laryngol Otol 115(6): 467474.

48. Tikkakoski T, Luotonen J, Leinonen S, Siniluoto T, Heikkilä O, Päivänsalo M, et al. (1997) Preoperative embolization in the management of neck paragangliomas. Laryngoscope 107(6): 821-826.

49. Mat Baki M, Clarke P, Birchall MA (2018) Immediate selective laryngeal reinnervation in vagal paraganglioma patients. J Laryngol Otol 132(9): 846-851.

50. Pollak N, Soni RS (2017) Endoscopic excision of a tympanic paraganglioma: Training the next generation of ear surgeons. World J Otorhinolaryngol - head neck Surg 3(3): 160-162.

51. Killeen DE, Wick CC, Hunter JB, Rivas A, Wanna GB, Nogueira JF, et al. (2017) Endoscopic Management of Middle Ear Paragangliomas. Otol Neurotol 38(3): 408-415.

52. Ohki M, Kikuchi S (2019) A Small Glomus Tympanicum Tumor Resected by Minimally Invasive Transcanal Endoscopic Approach. Case Rep Otolaryngol 2019: 1-5.

53. Gstoettner W, Matula C, Hamzavi J, Kornfehl J, Czerny C (1999) Long-term results of different treatment modalities in 37 patients with glomus jugulare tumors. Eur Arch Oto-Rhino-Laryngology 256(7): 351-355.

54. Offergeld C, Brase C, Yaremchuk S, Mader I, Rischke HC, Gläsker S, et al. (2012) Head and neck paragangliomas: clinical and molecular genetic classification. Clinics (Sao Paulo) 67(1): 19-28.

55. Persky MS, Setton A, Niimi Y, Hartman J, Frank D, Berenstein A (2002) Combined endovascular and surgical treatment of head and neck paragangliomas? A team approach. Head Neck 24(5): 423-431.

56. Boedeker CC, Ridder GJ, Schipper J (2005) Paragangliomas of the head and neck: diagnosis and treatment. Fam Cancer 4(1): 55-59.

*Corresponding author: Diego Duminy-Luppi†', Email address: ddumindu8@alumnes.ub.edu

Next Submission with BGSR follows:

- Rapid Peer Review

- Reprints for Original Copy

- E-Prints Availability

- Below URL for auxiliary Submission Link: https://biogenericpublishers.com/submit-manuscript/ 